\title{
Bilingual Teaching in Medical Colleges and Universities in China: Problems and Suggestions
}

\author{
Cheng Chen ${ }^{1,2}$, , Xuecheng Wang ${ }^{1}$, Xiangfa Zeng ${ }^{1}$, Fei Chen ${ }^{1}$, Yamin Jiang ${ }^{1}$ \\ ${ }^{1}$ School of Humanities and Information Management, \\ Chengdu Medical College, \\ Chengdu, China \\ ${ }^{2}$ Key Laboratory for NeuroInformation of Ministry of Education, Center for Information in Medicine, \\ University of Electronic Science and Technology of China, \\ Chengdu, China \\ *Correspondence: happycc886@126.com
}

\begin{abstract}
With the increasing demand for national talents and medical development of China, Ministry of Education of the People's Republic of China issued a document in 2001 to advocate the use of foreign language for specialized courses teaching. As it is emphasized that the important task of education development in China is to improve the internationalization level of education and cultivate international talents, many medical colleges and universities have been making continuous effort to equip medical talents with both professional knowledge and foreign language application skills. To probe into and then discuss on the present situation, the already achieved progresses and the current problems and weaknesses of bilingual teaching research and practice in medical colleges and universities in China, this paper makes a brief literature overview about the articles published in some core journals indexed by CNKI from 2002 to 2017, by selecting the Chinese words meaning "medicine" as the topic word and "bilingual teaching" as the key words. This paper summarizes the general situation of bilingual teaching since its pilot program, puts forward some suggestions in view of the existing problems, and expects to promote the development of bilingual teaching research and practice in medical colleges and unive rsities in China.
\end{abstract}

Keywords-Bilingual teaching; Medical colleges and universities; Problems; Suggestions

\section{INTRODUCTION}

With the acceleration of globalization, the cultivation of scientific talents in China faces great challenges. How to equip students in medical colleges and universities with capabilities to communicate and cooperate with international community has already become one of the focuses of higher education. Therefore, bilingual teaching in medicine has arisen.

Modern bilingual teaching stemmed from the 1950s and 1960s. With the acceleration of the European integration and the continuous consolidation of the status of English as the international common language, bilingual teaching has become extremely popular in Europe. In China, since Ministry of Education of China has issued document No. 4, i.e. Suggestions on Strengthening Undergraduate Teaching Work and Enhancing Teaching Quality in Higher Education Institutions, the practice and research of bilingual teaching in

This work was supported by the fund from Sichuan Foreign Language and Literature Research Center (No. SCWYH17-05). colleges and universities have been gradually emerging. This document clearly requires that colleges and universities actively promote bilingual teaching. Higher education institutions should strive to achieve a percentage of about $5 \%$ $10 \%$ of bilingual courses, especially in the high and new technology fields, and in some majors which urgently need talent training [1]. Since then, some colleges and universities have carried out bilingual teaching. In 2005, in the international context of improving teaching quality, Ministry of Education of China put forward further requirements for bilingual teaching in its No. 1 document, i.e. Suggestions on Further Strengthening Undergraduate Teaching Work in Higher Education Institutions. It requires that the quality of bilingual teaching should be continuously improved and the number of bilingual courses should be expanded [2]. Since then, researches and practice concerned about it have been steadily and dramatically increasing.

\section{GENERAL INFORMATION ABOUT PUBLISHED ARTICLES ON BILINGUAL TEACHING IN MEDICINE IN CHINA}

In order to make a comparatively comprehensive understanding of bilingual teaching practice and research in medical colleges and universities in China, this paper carries out a brief overview about the articles published in some core journals indexed by CNKI from January 2002 to December 2017 [3], including the Chinese Core Journal Criterion of PKU, Chinese Social Science Citation Index (CSSCI), and Chinese S\&T Journal Citation Report (CJCR). “医学” (meaning "medicine”) is selected as the topic word, and “双语 教学” (meaning “bilingual teaching”) is selected as the key words. By combining the two terms together, a literature search is made in CNKI database. Since some articles do not put "medical science" as the topic word, repeated searching works are carried out by combining the names of some other subjects and "bilingual teaching". Subjects in preclinical medicine mainly include genetics, anatomy, histoembryology, biochemistry, physiology, pathology, cytology, microbiology, etiology, immunology, neurobiology, and subjects in clinical medicine mainly include internal medicine, surgery, obstetrics and gynecology, pediatrics, stomatology, psychology, orthopedics, ophthalmology, oncology, dermatology, burns 
surgery, et al. Only the articles classified in medical science and technology category are involved in the statistics. Dissertations of master students and doctoral students, conference papers, newspaper materials, and articles with low relevance are all excluded in the statistical analysis. Finally, 110 articles are selected for further analysis and explanation. Fig. 1 shows the publication information of these articles.

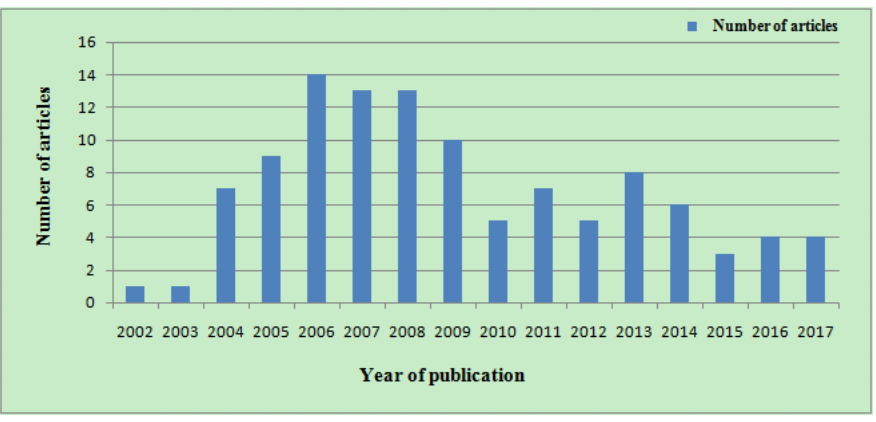

Fig. 1. Articles on bilingual teaching in medicine published in core journals indexed by CNKI from January 2002 to December 2017

According to these articles, bilingual teaching practice and research mainly focus on such aspects as the overall conception of bilingual teaching, practice and discussion, construction of teaching mode, application of different teaching methods, analysis of problems and effects, bilingual teachers, teaching materials, curriculum setting, and assessment mechanism. The frequently involved subjects in preclinical medicine include anatomy, pathophysiology, pharmacology, immunology and so on. Bilingual teaching research in clinical medicine mainly focuses on a general discussion on the teaching mode or method, with only a few taking a specific course as the research object, like rehabilitation medicine and stomatology.

\section{PRoblems And AnAlysis OF BILINGUAL TEACHING}

\section{A. Incomplete Understanding of Bilingual Teaching}

A unified understanding of the basic concepts of bilingualism and bilingual teaching has not been formed among domestic researchers and practitioners. In Longman Dictionary of Language Teaching And Applied Linguistics, "bilingual" is defined as "a person who knows and uses two languages" [4], and "bilingual teaching" is defined as "the use of second or foreign language for the teaching of content subjects" [4]. Accordingly, some domestic scholars hold that bilingual teaching is the teaching of various subjects in English language, while some other scholars hold that bilingual teaching involves two languages in one class. Therefore, disputes arise on the proportion of the use of two languages, attracting a large amount of related researches and discussions. A researcher in the Curriculum and Materials Research Institute of Ministry of Education of China holds the view that bilingual teaching is to directly apply a non-native language to the teaching of non-language subjects, aiming to synchronize the learning of a second language with the acquisition of knowledge in all subjects [5].

Referring to some scholars' views, the authors of this paper believe that bilingual teaching in medical colleges and universities in China generally involves applying Chinese and English language to the teaching of subjects in medical science. But bilingual teaching does not mean a simple mix of the two languages. A foreign language (usually English) can be used as the main teaching language, but since teachers are bilingual, the use of native language (usually Chinese) is also possible. Then it needs to be figured out whether the primary goal of bilingual teaching is the acquisition of professional medical knowledge or the improvement of foreign language ability. If the primary goal is to acquire professional medical knowledge, then the quality of language involvement might be ignored in the teaching process. But if the primary goal is to improve foreign language ability, then the effect of professional medical knowledge acquisition will be greatly reduced. Apparently, the two aspects are both significant. Therefore, the researchers and practitioners need to reconsider how to coordinate the primary and the secondary relationship between the two aspects. The authors of this paper believe that it would be better to regard the acquisition of professional medical knowledge as the primary goal, and at the same time, it is also necessary to improve the foreign language ability.

\section{B. Dilemma in Choosing Teaching Materials}

Many articles have explicitly mentioned the dilemma in the selection of bilingual teaching materials. Researchers and practitioners generally believe that bilingual teaching lacks appropriate teaching materials which are in line with the actual situation of students. In bilingual teaching process, many colleges and universities are faced with the difficulty when selecting among original English textbook, English textbook together with its Chinese version, and adapted or self-edited English textbook. The brief overview of the articles shows that a small number of students hope to use original English textbook because it is featured by high authority, large amount of information and abundant figures and examples. Therefore, students not only can reach for the frontier knowledge of the subject, but also can acquire, in an unconscious way, the thinking mode and handling approach that are consistent with the international practice. However, it also has problems, like the expressions are difficult, too native and foreign for the students to understand, the knowledge points are too sporadic with less systematic feature, the price is too high, and it deviates from the actual teaching content in some medical colleges and universities in China. A large number of students hope to use English textbook together with its Chinese version because that would reduce the difficulty in understanding. But the problem is two textbooks will absolutely add students' learning burden. Another choice is the adapted or self-edited English textbook, but it will be such a challenge for the editor because it requires a reasonably strong foreign language ability and a high professional level. Also it requires the editor to tightly follow up the latest development and knowledge in related fields, which is absolutely time and energy consuming and a copyright threat exists.

\section{Unreasonable Curriculum Setting}

The system of medical knowledge is enormous and the courses are various, so students suffer great learning burden and stress. Moreover, because bilingual teaching brings about the pressure of language conversion, acceptance and 
understanding and because students' foreign language levels are different, it is undoubtedly that bilingual teaching causes dual pressure for students in both professional knowledge acquisition and foreign language understanding, thus becoming much more time and energy consuming. To avoid the decline of the learning effect of professional systemic knowledge, many colleges and universities have compressed the teaching hours of bilingual teaching. Together with the situation that some colleges have unreasonable and imperfect settings for bilingual courses, bilingual teaching has become a mere formality, causing a great gap between the original intention and the actual effect of bilingual teaching.

\section{Imperfect Assessment Mechanism}

The most highlighted question about assessment mechanism is which language should be used to give questions and answers in the test. Strictly speaking, to give the questions and answers in English can best meet the bilingual teaching standard. However, as bilingual teaching in medical colleges and universities in China is restricted by many factors like students' English level, questions in the test are often given in English or even In Chinese, and students are allowed to answer In Chinese. It is absolute a deviation from the goal setting of bilingual teaching and is contrary to the original intention of bilingual teaching. In addition, the current assessment mechanism focuses on the summative assessment, and the formative assessment ways are quite diverse and lack unity. Not so many colleges and universities adopt both the summative and the formative assessment at the same time, indicating that the assessment mechanism is imperfect.

\section{E. Insufficient High-quality Teachers}

Bilingual teaching expects and demands high-quality teachers, who are well equipped with sufficient professional knowledge accumulation and good foreign language skills. Currently, only a small number of teachers can basically meet these requirements. Many other teachers still face the foreign language barrier because of their insufficient expression ability. Some articles reviewed in this paper use quantitative measures to measure students' assessment of teachers, and the results show a significant difference in the recognition degree of bilingual teachers among different colleges and universities. Teachers with solid professional foundation, good language skills, overseas study or work experience are highly welcome and undoubtedly a priority in bilingual teachers selection. Unfortunately, the number of such excellent teachers is limited. Short-term overseas training of teachers cannot fundamentally solve the problem of the lack of good teachers. In addition, the introduction or training of teachers is restricted by many factors like the level of personnel and the input level of financial resources. Since having good teachers is the key factor to guarantee the quality and effect of bilingual teaching, the introduction or training of teachers needs to be solved urgently.

\section{F. Unsatisfactory English Level of the Students}

Some students in medical colleges and universities in China may have relatively satisfactory English reading and writing abilities, but their listening and speaking abilities are generally low. Although they realize the importance of English and the significance of bilingual courses, they still feel frustrated and tired in bilingual classes because of their heavy workload, the examination system, their comprehensive English ability, the language environment and so on. It is quite natural for them to feel frustrated in acquiring professional knowledge and improving the English language ability, so they tend to give negative feedback to bilingual teaching. Naturally, even though good teaching materials, reasonable curriculum setting and excellent teachers are given to bilingual teaching, its effect will still be restricted by students' unsatisfactory and insufficient English level.

In addition to the aforementioned problems, bilingual teaching in medical colleges and universities in China still confronts with some other problems, such as the deficient construction of the overall teaching mode, lack of systematization, inadequate teaching consistency, less diversified teaching approaches, outdated teaching mode, insufficient attention from some departments, lack of cooperation between relevant departments or schools, and so on. In order to effectively respond to the call of Ministry of Education, it is necessary to adjust and improve the situation of bilingual teaching from many aspects.

\section{SUGgESTIONS FOR IMPROVEMENT}

The brief overview of articles indicates that whether it is theoretical research or teaching practice, it is difficult and problematic to carry out bilingual teaching in China. Therefore, the following suggestions are put forward to explore some bilingual teaching concepts and approaches adapted to the actual situation of bilingual teaching in medical colleges and universities in China.

\section{A. Clarify the Goal of and Attach Enough Importance to Bilingual Teaching}

As mentioned above, it would be the best to consider the primary goal of bilingual teaching in medicine as the acquisition of professional medical knowledge. The improvement of foreign language ability is also expected at the same time. To be clear about this at the beginning will help teachers to set up teaching syllabus, arrange teaching schedules, organize class activities, allocate the proportion of the use of two languages, and carry out reasonable assessment mechanisms.

Meanwhile, bilingual teaching does not involve only students and teachers, but also many other factors. To achieve a good teaching effect, schools, departments, offices and teaching staff need to attach enough importance to bilingual teaching, provide adequate project and fund supports, establish a stable and sustainable policy environment, set reasonable curriculum, allocate enough teaching hours, and carry out collaboration with each other.

\section{B. Strengthen the Introduction or Training of Excellent Teachers}

The quality of bilingual teachers is one of the decisive factors of bilingual teaching effect. In the overviewed articles, the degree of recognition of bilingual teachers is quite 
different among students from different colleges and universities. Those with better conditions, such as "211 Project" and "985 Project" higher medical institutions, have relatively high-quality teachers with high recognition from students. The possible reason may lie in that the level of professional knowledge and foreign language ability of their teachers themselves are relatively high, the importance attached to teacher introduction or training is relatively greater, the fund and policy supports provided by those schools are relatively sufficient, and the atmosphere of bilingual teaching is relatively strong, so that their teachers can grow up and develop steadily for a long time. Therefore, it is advisable that other colleges and universities learn from the good examples as possible as they can so as to get the strong power for a satisfactory bilingual teaching.

\section{Diversify Teaching Models and Make a Second Development of Teaching Materials}

Teaching modes mentioned in most of the overviewed articles mainly include "immersion program", "transitional bilingual education", and "maintenance bilingual education". It is suggested that if students' level of foreign language ability is relatively high, then it would be a good idea to adopt immersion program teaching mode, which means to use the foreign language in class in order to enable students to learn foreign language expression habits and technical terms as much as possible while mastering the professional knowledge. However, it is less likely for medical colleges and universities in China to achieve complete immersion program teaching because of the mother tongue environment existing on campus. If students' level of foreign language ability is medium, then it would be a good idea to mainly adopt transitional bilingual education mode, which means to decide on the beginning time of foreign language teaching according to students' learning situation. If students' level of foreign language ability is relatively low, then it would be a good idea to mainly use maintenance bilingual education mode so as to reduce the difficulty of bilingual teaching and strive to realize the primary goal of bilingual teaching.

However, the teaching mode is not static and students' situation may vary. Therefore, in the teaching process, an adjustment of the teaching mode and a second development of the teaching materials should be made according to the actual situation, and some other auxiliary means should be employed flexibly. Once a teaching mode which meets the characteristics of colleges or universities and students at all levels is established, and a sound second development of teaching materials is achieved, both the teachers and the students will enjoy and benefit a lot in bilingual teaching and thus the teaching goals and objectives can be guaranteed to a certain degree.

\section{Improve the Assessment Mechanism and Guarantee the Teaching Quality}

At present, the assessment mechanism of bilingual teaching is mainly a summative assessment, which is not conducive to the supervision of the learning process. Therefore, it is suggested that teachers simultaneously adopt practical and unique formative assessment mechanism according to the nature, characteristics, and difficulty of the course as well as the actual situation of the students. When a positive relationship and an effective interaction between teachers and students are established, it will be helpful for the teachers to supervise students' learning process, get their feedback in time, and adjust the teaching strategy timely. The effective combination of formative assessment and summative assessment can be regarded as a comparatively scientific and comprehensive assessment mechanism, which can guarantee the quality of bilingual teaching from various links.

\section{Conclusion}

The brief overview of the articles on bilingual teaching in medicine that are published in the core journals indexed by CNKI from January 2002 to December 2017 reveals that there are still many problems in the bilingual teaching in medical colleges and universities in China since its pilot program. Some colleges and universities have come up with corresponding solutions to the highlighted problems. However, the current problems are not thoroughly solved. Both theoretical research and teaching practice of bilingual teaching in medical colleges and universities in China are progressing in twists and turns. It is widely acknowledged that bilingual teaching is considerably significant for the standardization of education, the cultivation of medical talents with professional knowledge and foreign language ability, and the internationalization of medical career development. Therefore, it is urgently necessary to take some effective improvement measures and make every effort to remove the unfavorable conditions so as to maximize the role of bilingual teaching and ultimately realize the goal of bilingual teaching and achieve a win-win situation for students, meaning both the acquisition of professional knowledge and the improvement of foreign language ability.

\section{REFERENCES}

[1] Ministry of Education of the People's Republic of China, Suggestions on Strengthening Undergraduate Teaching Work and Enhancing Teaching Quality in Higher Education Institutions. Beijing, 2001. (In Chinese)

[2] Ministry of Education of the People's Republic of China, Suggestions on Further Strengthening Undergraduate Teaching Work in Higher Education Institutions. Beijing, 2005. (In Chinese)

[3] W. Qingyi, W. Ting, and Z. Yumei, "Review and analysis of bilingual teaching in medicine in China-based on articles published on core journals indexed by CNKI from 2002 to 2016," Chongqing Medicine, Chongqing, vol. 46(53), pp. 5036-5038, December 2017. (In Chinese)

[4] J. C. Richards, and R. Schmidt, Longman Dictionary of Language Teaching and Applied Linguistics, 3rd ed. Beijing: Foreign Language Teaching and Research Press, 2003.

[5] W. Benhua, "Conform to the trend of the times and create a strong bilingual learning atmosphere," Curriculum, Teaching Material and Method, Beijing, vol. 6, pp. 49-51, June 2003. (In Chinese) 